\title{
CONSTRUCTION OF BICYCLIC RING SYSTEMS VIA [3,3]-SIGMATROPIC REARRANGEMENT STRATEGY
}

\author{
A.V. Kurkin', Y.V. Ulianova², E.R. Lukyanenko' \\ ${ }^{1}$ Lomonosov Moscow State University, Department of Chemistry, Moscow, Russia \\ ${ }^{2}$ D. Mendeleev University of Chemical Technology of Russia, Moscow, Russia
}

DOI: 10.19163/MedChemRussia2021-2021-32

E-mail: kurkin@direction.chem.msu.ru

In a recent work, we have reported a case of an highly stereocontrolled synthesis transfused octahydrocyclohepta[b]pyrrol-4(1H)-ones via the aza-Cope-Mannich rearrangement in either the racemic and enantiopure forms (see the Scheme).
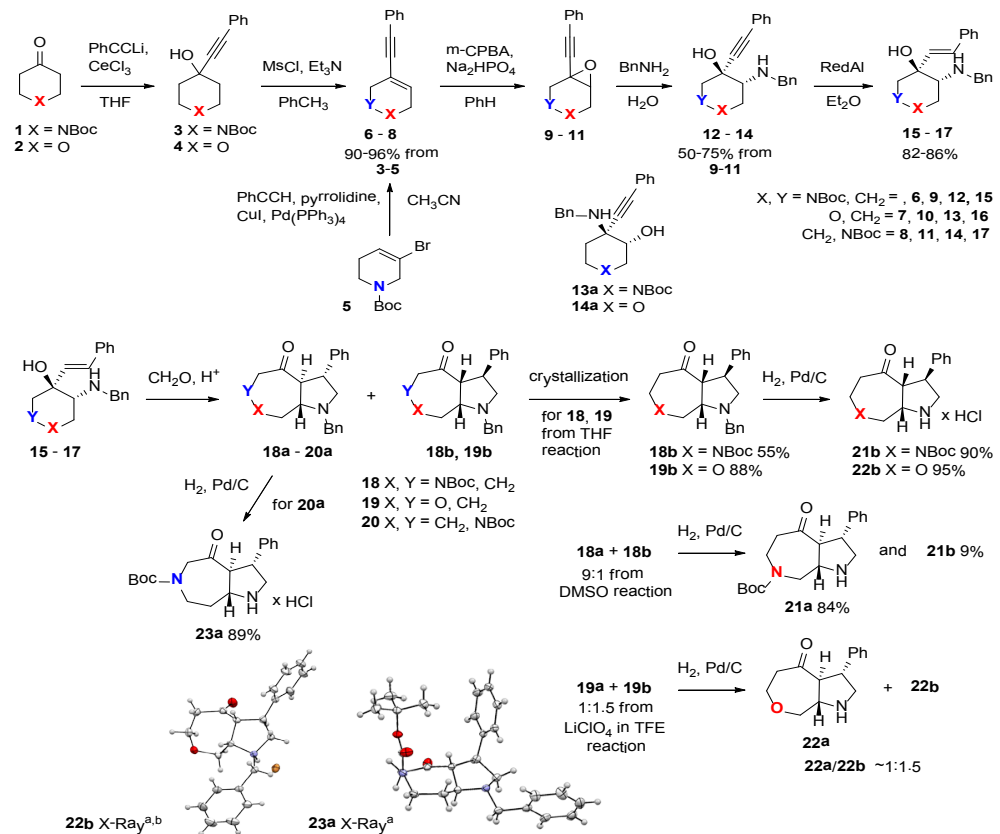

$18 X, Y=N B o c, \mathrm{CH}_{2}$

$19 X, Y=O, \mathrm{CH}_{2}$

$20 X, Y=\mathrm{CH}_{2}, \mathrm{NBOC}$
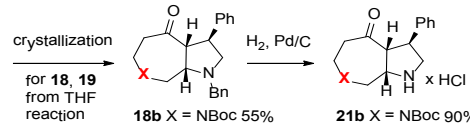

$19 b \times=088 \%$

$21 \mathrm{~b} X=\mathrm{NBOC} 90 \%$ 22b $\mathrm{X}=095 \%$
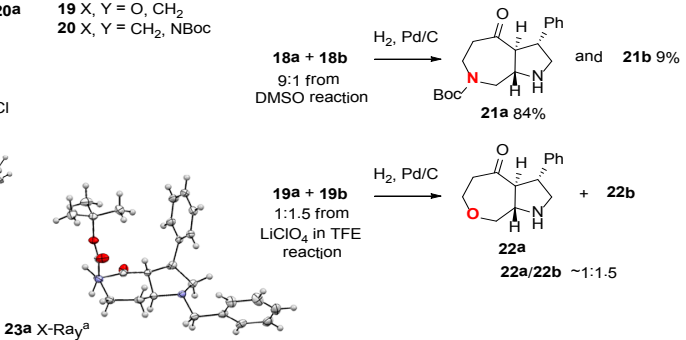

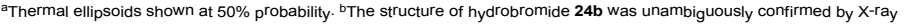

We have developed an efficient and stereoselective synthesis of cis- and transfused decahydropyrrolo[2,3-c]azepines, octahydro-1H-oxepino[4,5-b]pyrroles, and decahydropyrrolo[2,3-d]azepines using the aza-Cope-Mannich reaction. The target scaffolds were achieved in 6-7 steps from commercially available starting materials and could be obtained in racemic form on a multi-gram scale. The corresponding individual enantiomers were also synthesised using (R)-1-phenylethylamine as a chiral pool.

This study was supported by the Russian Foundation for Basic Research

(Project No. 20-015-00291). 